\title{
Improvements In The Strategic Use Of The Marketing Matrices Applying Dynamics Parameters Based On Time: A Better Analysis Of Prospect
}

\author{
Daniela Navarra \\ BA in Marketing Management at Polimoda International Institute for \\ Fashion Design Marketing, Fellow in Int. Marketing \\ Luca Scaini \\ PH.D. in Marketing at Ashley University, USA, \\ MA in Arts at Università di Urbino, Italy \\ Senior Academic Manager and Research Professor of Fashion Marketing at \\ IFA Paris, Shanghai Campus, Shanghai, China \\ Fellow in Int. Marketing at CASIA, \\ Center for Advanced Studies in Internationalization Processes in Asia
}

doi: 10.19044/esj.2016.v12n10p1 URL:http://dx.doi.org/10.19044/esj.2016.v12n10p1

\section{Abstract}

Matrices are among the main analytical tools used in marketing. The present paper focuses on the possibility to make them consistently explorative of a business prospect, not just in a mechanical way but in a logical and quantitatively probabilistic way. Matrices, being static, appear in contrast with the real meaning of marketing itself (being a verb it is an action). Actually, lack of the matrices is that they do not consider the temporal evolution and offer a very simple and static frame and indeed a snapshot of the business environment. The purpose of the present paper is to understand "to what extent the matrices can be improved to perform dynamic prospective analyses, thanks to specific improvements":

- Complex variables

- Cartesian plan and derived curves

- Use of the chronotropic quadric-dimensionality through spacetime factor influencing the mechanical results

It is considered only the case of the four cells based matrix (and experimentation is pursued via the Ansoff's one), leaving the nine-cell based matrices to the field of actual limitations and future improvements. The standard format can be implemented by the adoption of new format and complex variables, which are holistic, and through the utilization of a temporal ratio, to show the temporal dynamism and make them suitable for 
prospective analysis and become a tool of management of the company's evolution.

Keywords: Ansoff Matrix, Strategic Management, Spacetime Dimension, Analysis Tools, Business Performances

\section{Introduction and state of the art}

Matrices are widely used in many sciences, including economics, and offer the possibility to express and show articulate concepts in an easy way. Actually, they are useful to write in a compact form linear system and this is the reason why marketing has adopted some of them for different broad analysis, relatively scoped on a portfolio of activities. Marketing matrices are actually based on four or nine cells, basing sometimes on the Cartesian plan as well, especially to render a positioning. Matrices are fundamental analytical tools, but now they come without any relationship with diagnosis (if not probabilistically intended, Mokwa 1986), and without any dynamical operative applicability: it is rather difficult to define some, if not winning, correct strategy basing the whole strategic analysis on a limited scoped study (Sun Tzu cited in Chow-Hou 2003) and without angled tools neither such strategy is applicable without a solid and robust management. The objective lack of a parameter "time" reduces the utility bound with profit of the matrices. In fact they appear like enforceable in order to become tools both efficient and effective in the logical process of optimization of company's performances (Thompson 2001). Actually, they are tools of analysis and management, offer shortcuts to possible strategies and show possible criteria to allocate resources in different activities and to economically solve, at the same time, more linear systems with the same coefficients and several known terms (Hoffman \& Kunze). Basically they act in a very mechanical way of action-consequence, where "action" is more properly a "state-of-theart" and "consequence" is merely mechanical, if "X=1, $\mathrm{Y}=1$, then $V^{\overrightarrow{ }}=$ $\int(x ; y)$ ", but without any interference from other variabilities. Moreover, they can also be used to analyze and manage a certain situation, seen like the result is a snapshot of a potentially correct situation, or seen like a fake evolution of the situation, which is built on a certain static and limited analysis and which offers a mechanical consequence without any prospect (Scaini 2015). Such system of work is basically founded on two parameters, very seldom complex and always static, that depends on what the goal of the matrix is: changing the parameters that make them, being in mutual function between each other, the result itself changes mechanically, producing mechanically just another snapshot. They work under the following prospect: - $\quad V^{\rightarrow}=\int(x ; y)$, where the vector resulting is equal to the mutual function of $\mathrm{X}$ and $\mathrm{Y}$, or 


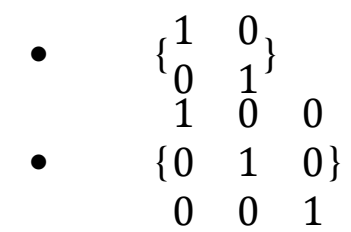

Especially in marketing, many among the common portfolio matrices rely on the second and third typology, which are characterized by the fact of crossing one external dimension (usually market or related parameters, concerning the attractiveness of the ambience where the business is competing) with one internal dimension, concerning the competiveness of the company. Even though there is a little number of examples of matrices linking the evaluation of performances and assets (Thompson 2001; Johnson \& Scholes 1997; Mokwa \& Permut 1981, Mokwa 1986), they are not really empowered for practical uses, due to the complexity of utilization. Following a better analytical definition of the role of matrices, they are gradually developing ways to more articulated and realistical prospect (at least, in the formulation of a potential and probabilistic results that goes beyond the mere mechanical prospect), and this thanks to the possibility to assign the matrix complex parameters on both axes, sort of multiple measures to assess business strength and industry attractiveness (Boundless 1970; Scaini 2015).

It became even more relevant and recommended (Collesei 2000; Vescovi 2008) to add financial assesses, for example those able to show the single business' provision to a gross turnaround or its contribution in terms of net gain, or the effects on the financial dimension of a company (in terms of resources absorption and cash generation). Fact is that crossing the variables on the axes it is found either a vector (usually a linear one $\vec{v}$ ), or a frame with the mentioned four to nine cells. Second case is the one from where present paper starts, stating as an actual limitation and future (recommended) improvement research, the study of the nine cells matrices. Actually, as far as today the utilization of matrices appears limited and hindered in its full deployment due to the objective inability to render dynamic analyses because of the use of parameters that are very static and mechanical; in fact present paper proves that even complex assesses are useless for such dynamic representation without taking in good account time and prospective assessments. The actual state of the art gives evidences of a development blocked on a mechanistic use, poor proactive and scarce dynamic able to offer a real integration in a company strategy, being instead more useful to tactical analyses of a short term (Scaini, 2015). Focusing on the four-cells based matrix, it is arguably a kind of matrix that is widely used, easy and extremely mechanical and static, offering a minor possibility of action than the nine cells based ones. Due to its structure, this matrix is linked with the lack of dynamic elements and offers a punctual snapshot of a 
certain situation accordingly with an eventual vision of the possible dimensions and company's performances in action. Just to mention, the biggest difference between the nine cells and four cells based matrices is that the nine cells based one suggests a less mechanical use and could be used in a slightly dynamic way to prospect. To better shape the four cells one, over the years were added several add-ons and improvements, among which the paper mentions only the slightly strategic and perspective empowerment suggested by Collesei (2000) and Vescovi (2008). For instance, GE/McKinsey matrix adopted here for experimentation (Boundless 2015), compared with growth-share matrix or BCG matrix (Henderson 1970), offers a structure that is capable of a deeper and more sophisticated analysis, crossing both the typical external and internal factors and assessments acting on the attractiveness of an environment and competitiveness of a product, even though it is still impossible to work on any temporal evolution and prospect. In both cases, matrices’ format is very basic, due to need of simple representation of different parameters and the immobility or the lack of dynamic perspective is caused by the subjective observation and consequent general and mechanical positioning in a certain frame, consequent to predetermined parameters, without any evaluation of possible affecting conditions. Present paper suggests with evidence of experimentation, the idea to adopt an objective, arguably quantitative observation, linked to the competitive framework or other comparative conditions, eventually less mechanical. Actually, it is caused by the practical inability to represent:

- Development of a prospect situation

- $\quad$ Probabilistic or statistically probable evolution, better than a merely mechanical one

- $\quad$ Possible analysis of possible future scenario

Actually, the general idea is to find a way to transform linear mechanical vectors into more realistic curved vectors, making matrices way to potential realistic prospect. Nowadays it appears being more convenient for an evaluation of a quick resume of the strategic business units. Instead, paper suggests, it would be more convenient and practically useful to explore a way through which it would be possible to use them as a tool to allocate resources to boost a certain activity, logical and probabilistically true consequence of a situation (Collins, Campbell \& Goold 1999). The scholars mentioned, as well as the concept itself of a dynamic system which paper is focalizing on, starts from the necessity to build a model, possibly mathematical, basically able to describe the temporal evolution of all systems accordingly with mathematical laws which bond the actual snapshot with a possible non-mechanical prospect.

\section{Definition of the problem: management through four-cells matrix}


The very first concern is the possibility to use the time $(t)$ on the axes as part of the mixed parameters. It is useful to understand the evolution, better than the situation. The second concern is about the overlap of the traditional matrix on a Cartesian plan, which is able to offer a better view of the spacetime evolution. Since reason of existence of cells-based matrices is their easiness of use and crystal clear reading, and the goal is to get a snapshot of a linear equation, which is simple enough, the consequent limit and the actual research question is "to what extent matrices are exhaustive of a snapshot and useful to predict possible future frameworks?” In fact, under definition of strategy, which is the real concern and purpose of a well scoped analysis via matrices, it is possible to find the intimate practical reason of present research: "strategy" is the definition of a model that coordinates goals, policies and main lines of behavior of an organization in a consistent and solid synthesis (Quinn 1980). Starting point for a correct definition is the process of analysis itself, in which not only external elements, but also internal ones need the analysis, which is both punctual and evaluative. Strategy, like the attempt to rationalize an action should be bond with the realization of means and tools in the disposition of a company (what?) and its possibilities to operate with them (how?) in order to reach a certain goal fixed (why?). Those goals will not be necessarily "easy to get”, but at least realistic, solid, consistent for the company both under the point of view of economics and financials, it means efficient and effective (Thompson 2001). All this is actually missing, observing the problem of use of matrices under the lens of the Thompson matrix (2001) and adopting the methodology of analysis of matrices through another matrix. Present papers give evidence of the actual limitation and need of the present research to improve an actual operative and strategic limitation of marketing and strategic business.

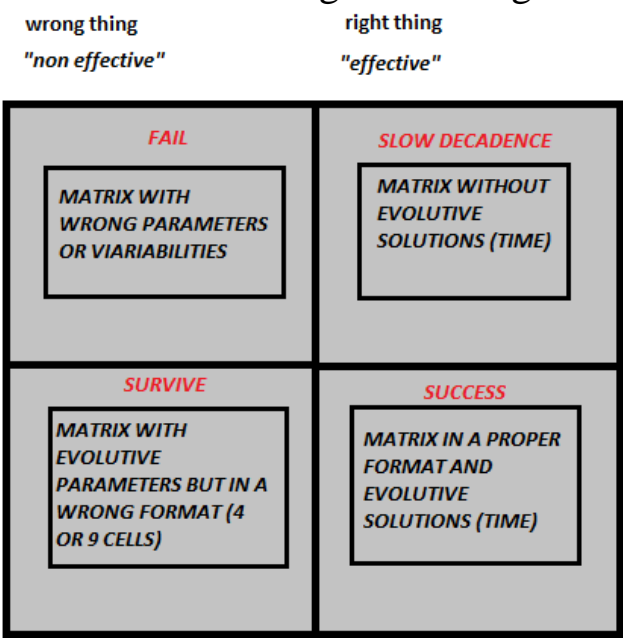

Fig 1: Adapted from Thompson, 2001: Effectiveness and Efficiency of the Use of Matrixes in Marketing 
Actually matrices are acting in the frames of decadence and survive and present paper intends to prove that some following innovation introduced can boost to a better use of matrices, which is practical and not merely theoretical. As shown, the concept itself of analysis is often mishandled by matrices' adoption to an immobility, instead it is really a dynamic action of factorization, observation, interpretation and reconstruction of a possible outcome that is originated by a question and acknowledged through the management. Time's introduction as a parameter may return the process to dynamical analysis in a linear sense, as suggested in an up to date study about the application of time as a parameter to the matrix of Ayal \& Zif (Scaini 2015). It is important to spot how matrices are executed in a very isolated way both in a time dimension and in a real space dimension (concepts that are commonly linked in physics): elements are considered in a unique condition, without any possible influence of future changes or interaction in the spacetime dimension and result is a basic mechanical consequence. In physics, the timespace is a mathematical model combining those two elements in a continuum and proves the quadricdimensional structure of the universe $\left(4^{\text {th }}\right.$ dimension is time itself, Sartori 1996). It is enough to prove the importance of such dimension in any mathematical representation of an event (Barrow\&Tipler 1988). Example is: if a company is a certain position " $\mathrm{A}$ ", then a consequence " $\mathrm{B}$ " must happen, without mentioning that in the spacetime frame passing from " $\mathrm{A}$ " to " $\mathrm{B}$ " something “ $\delta$ ” (interference) may happen that influence " $\mathrm{B}$ ” itself like “ $\delta \pm x$ " (or even in more complex ways of interference). In marketing matrices, dynamism results only from the management, and it is a fake dynamism, being just the consequent snapshot, mostly based on a partial outcome of mechanically possible analysis: it is the total of actions put into practice in order to reach the recommended goal originated by the elements of analysis allocated in the matrix. Such goal is basically preassigned as the unique possible consequence of a starting point. Dynamic analysis is instead fundamental to maintain a constant growth of the organization, it implies:

- Monitoring of activities and functions during their development, making them statistically possible and (and not only) mechanically consequential;

- $\quad$ Continuum of processes of analysis and revision of results;

Those operations are needed for the prospect and evaluation of future conditions. Improvement of strategic use of matrices can pass through mixed parameters, which are made of different holistic factors, among which there is time " $t$ ", as the actual proposal to correct a scholarly discussed limitations and a business acknowledged obstacle to a further analysis development. 


\section{Hypothesis: dynamic and cartesian plan as the main analysis improvement tools}

For the concern of present paper, innovations are applied to the Ansoff's matrix (Ansoff 1957), which is a 4-cells based basic tool of analysis for marketing strategy. It consists of a planning tool able to help the business development to define its own structure and growth strategy in the future. This matrix is based on market and product on the axes. A basic explanation of the matrix is useful for the purpose to show its actual limitation. In practical terms the matrix is actually split into 4 cells created by two dimensions: Product (X-ax) and Market (Y-ax). Both Product and Market Dimensions are furtherly split into old (actual) and new. Accordingly with product and market typology or, under unconventional theories, clients (Locke 2001) it is possible to snapshot in which cell a company is acting, and eventually, once the position it is known, this matrix may refer to some mechanical possible actions to perform. There are four potential option possible, and indeed no one seems wrong, being just mechanical consequence of a starting position bond to a corporate strategy without any prospect of attention to external variabilities and in no quadric-dimensional environment.

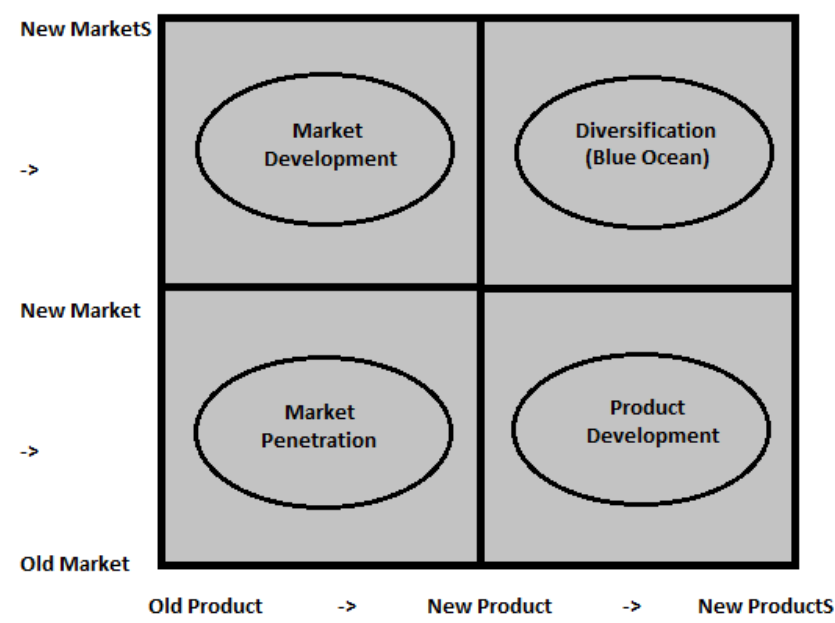

Fig. 2: Adapted from Ansoff, 1957: Ansoff Matrix

- $\quad$ Market Penetration: company enhance its market quote in an actual frame

- $\quad$ Market Development: company penetrates new markets in order to sell existing products

- Product Development: company's efforts are devolved to the creation/innovation of new products or empowerment of a line to be sold in the actual markets 
- $\quad$ Diversification (possibly Blue Ocean): company decides to penetrate new markets innovation or developing new products. Three possible diversifications are indeed recommendable:

- $\quad$ Concentric: company launches new products that are indeed similar to existing ones to be placed in a new segment

- Horizontal: company launches new products linked with actual ones, to be placed in the present segment

- $\quad$ Conglomerate of Diversification (or lateral): company trade new products unbend from previous ones and placed in new segments.

Upon this example the 4-cells matrices are strongly improvable in terms of prospect and planning, in order to practically render its strategic purpose, merging it into a quadric-dimensional framework.

2.1 First innovation which present paper suggests is the localization of three different macro-environments touching the possible evolution of a corporate business, actualizing the present business' course:

- $\quad$ Multinational (when a company insists in developing several markets leaving the products' innovation to a secondary role)

- Multiproduct (when a company diversify products or insists in a constant innovation way to competitiveness in usual markets)

- $\quad$ Blue Ocean or Diversification (Kim \& Mauborgne 2005).

This is a graphic representation of the whole strategic environment:

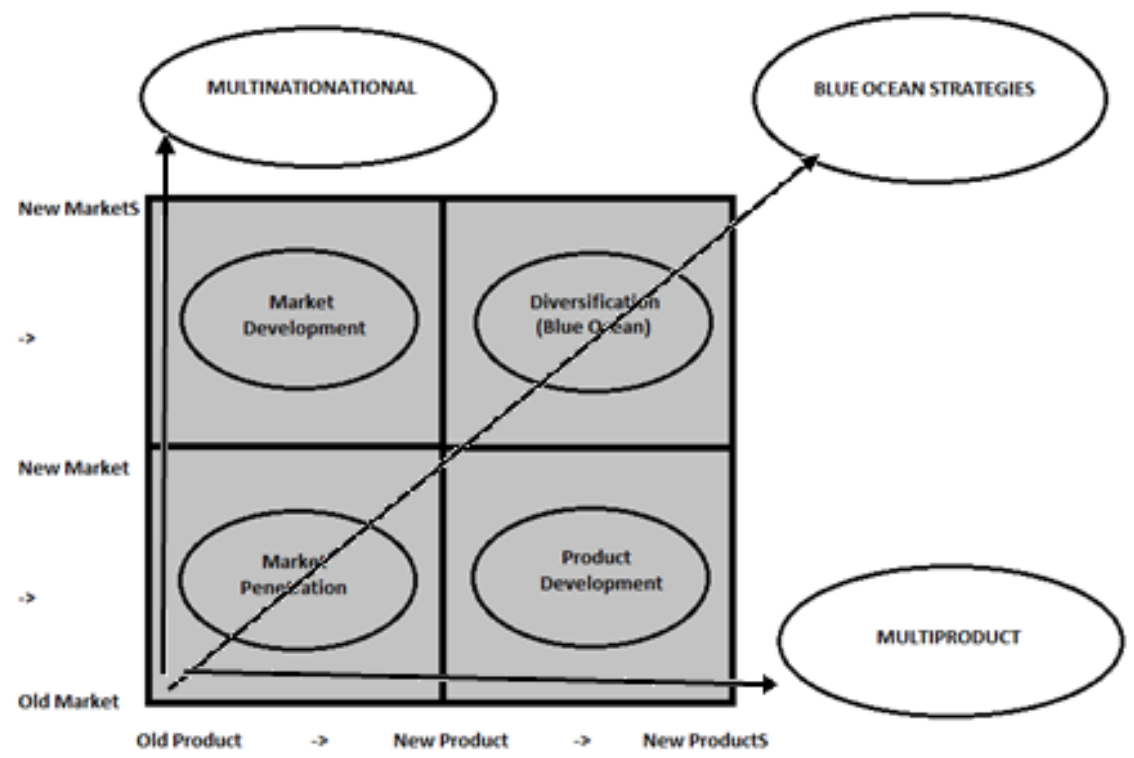

Fig. 3: Adapted Ansoff Matrix with external environments

2.2 Second innovation lies in transforming the matrix into a Carthesian Plan. Way to make the 4-cells base matrices, represented here by 
Ansoff's one, more dynamic and not just to actualize mechanical results, but to manage their real evolution, is to represent it through a Cartesian plan, present paper suggests. Such plan is marked with complex variables (various factors bond with timespace). Those make the vector $(v)$ able to represent the constant time $(t)$ evolution $(\mathrm{v}=t)$ and curves derived able to represent the strategy evolution.

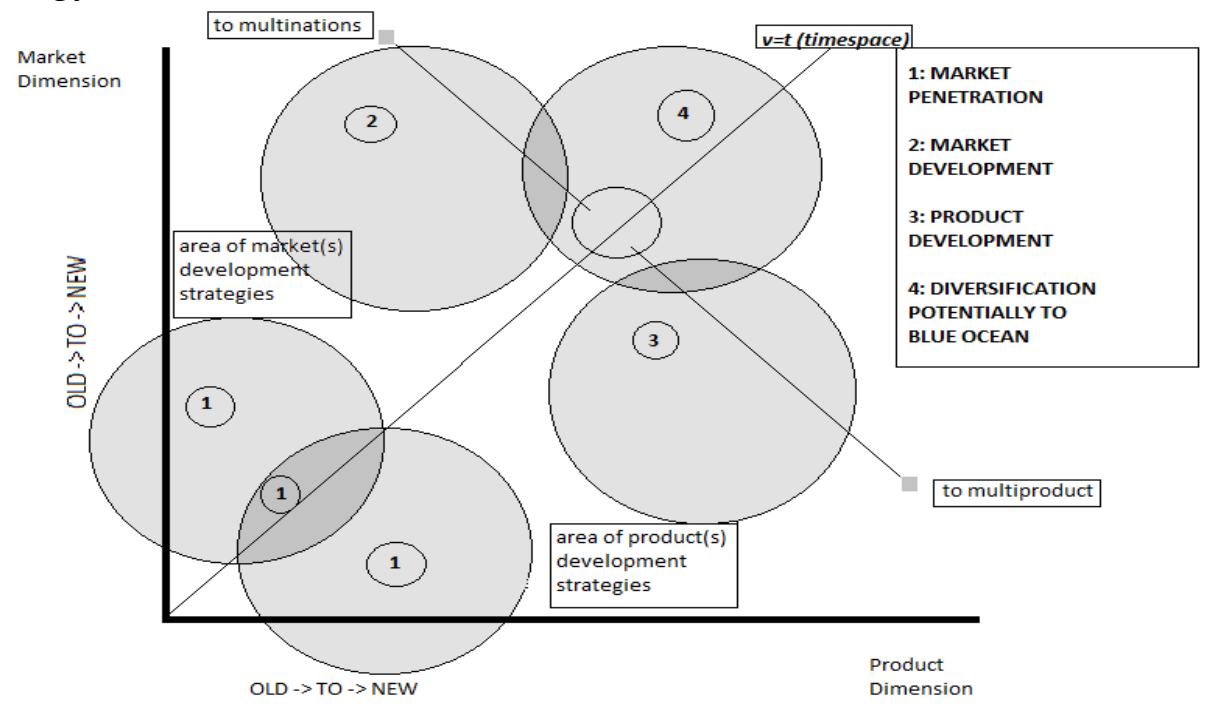

Fig. 4: Ansoff Matrix with Mechanics Adapted to a Cartesian Plan Present Cartesian Matrix shows:

- $\quad$ Use of complex variables in a timespace quadric-dimensional way (old to new, representing the time progression). It is kept on $\mathrm{X}$-ax the Product Dimension and on Y-ax there the Market Dimension;

- The same cells of the traditional matrix are localizable on the Cartesian plan. Anyway, they are represented more likely "in a possible logical development", not in a mandatory mechanical one and anyway way to success is represented with a deviation (influence " $\delta \pm x$ " that creates a curve), showed in the next figure, nr. 4;

- Eventually the starting position and the final position analyzed through a course.

Such dynamism and prospect of development is represented under the form of curves, ideally:

- $\quad$ Concave Curve (A) : Business moves toward Market Development

- $\quad$ Convex Curve (B): Business moves toward Product Development

- $\quad$ "S" and "reversed S" Curve: Business moves throughout a Balanced Development

Actually, the presence of a logical and natural path represented by curves derived from differential equations (Burkhoff, 1927; Hirsch, Smale \& 
Devaney 2003) can grant the evidence of the innovative idea introduced here and after. The matrix is not any more bond to a snapshot of a state, but it is affected by conditions of interference notable only during the deviation actuated in a certain quadric-dimensional frame and influencing any mechanical result, which becomes a prospect (for theoretical examples, see Alligood, Sauer \& Yorke 2000; Katok \& Hasselblatt 1996). In fact, the presence of "S" curves (or any "S-reversed") is representing the optimal development balanced between time and strategy, as showed in fig nr.5 (below).

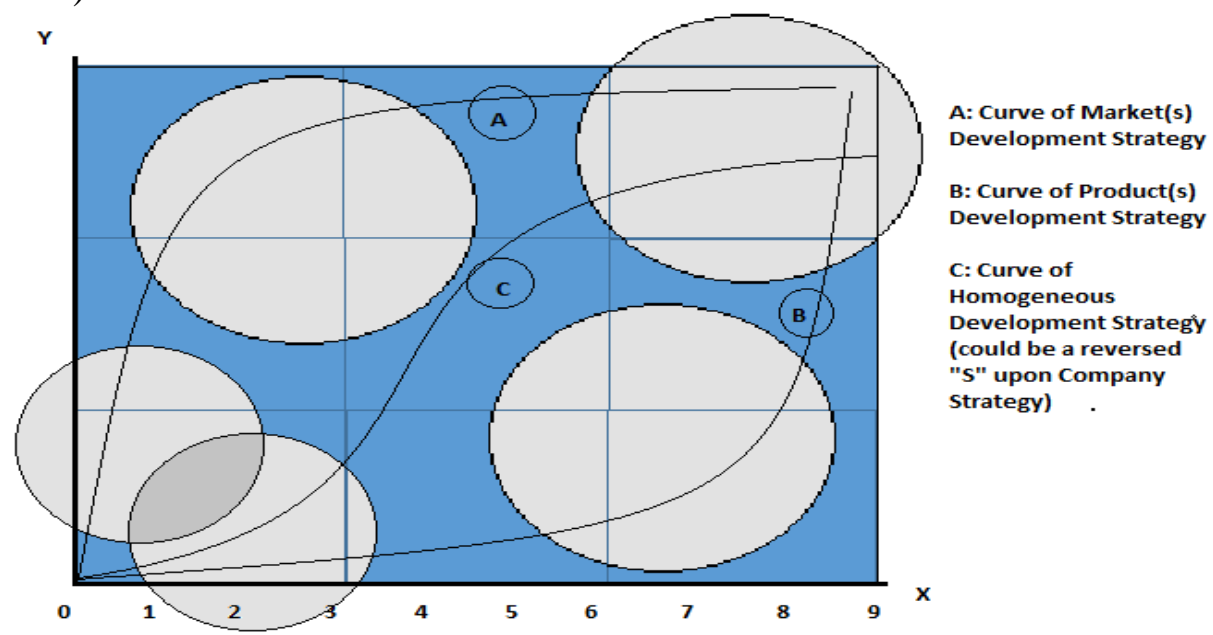

Fig. 5: Matrix of Ansoff: Mechanics and Curves of Prospect Development

Accordingly to the curves, the original content is kept in his substantial meaning: in fact a business can be developed alternately in a number of markets with one or a few products, without any prior innovation, or through a number of products (or versions of the same one, enlarging the line or its profoundness), prior to enter several markets. In these cases a business can be launched successfully through a product on more markets or be concentrated in one market developing more products. The mechanical process is unchanged, but empowered in its possibilities of setting up a prospect (throughout a course) and in its possibility to spot forces and events acting during the whole process. What really changes, is the way-how the analysis is pursued: dynamically and quadric-dimensionally (Hirsch, Smale \& Devaney 2003) and, consequentially the result of the analysis itself, the purpose of it and the different action that can be taken. The final and optimal position of $v=f(X ; Y)$ (and the average position compared with business) should be always the final cell, considering true the function of spacetime (quadric-dimensionality of linear equations). This final cell, under Ansoff, is called Diversification or in the early original evolution suggested, it became "Blue Ocean". There are, moreover, two peripheral areas of excessive 
concentration of strategies: they represent an excess of markets with a few products or an excess of products in a few markets, potentially risky position of development where a company risks to focalize too much in one single instance better than maintaining a balanced position, even though yet clear and consistent in the strategic competition. Those position can easily rely on the "Icarus Paradox" (Miller 1990, 1992; Vermeulen 2009). This full framework allows to bond causes and consequences in a well-defined frame of spacetime, where deviations from the vector is in a constant action and are basically caused by external factors as well as paraeconomicals ones (Scaini 2015; Fogel 1994). The development or the eccess of specialization in one or another dimention can be spotted and corrected in case it may lead to dangerous and potentially riscky courses. The purpose is not to draw a different curve, but to spot the menaces and an uncorrect development or to be aware of a situation in action and being able to make any possible correction just in time. It is a reliable management of the strategic process applied to a prospect that is mathematically consistent.

2.3 A third, last innovation concerns the adoption of some metrical scale, which might result as very useful to fix keypoints, tasks, to measure quantitatively the performances and to join a Ganntt diagram to manage the single tasks, even though slowing down a bit the process and cutting the easyness of the use of the matrix.

\section{Experimentation: the validity of the introduced improvement}

3.1 Experimentation Company " $A$ ": " $\mathrm{A}$ " is a Private Management School starting its operative activity in 2003. The check points are numbered 1,2 and 3 and represent the three main moments where an analysis of development resulted vital. The present analysis compares the original Ansoff Matrix adopted and the Ansoff Evolved, which is applied to present case lately. Figure below shows what the evolved matrix may present, compared with the classic model, if early adopted in order to study, analyze and plan a strategic development of the business.

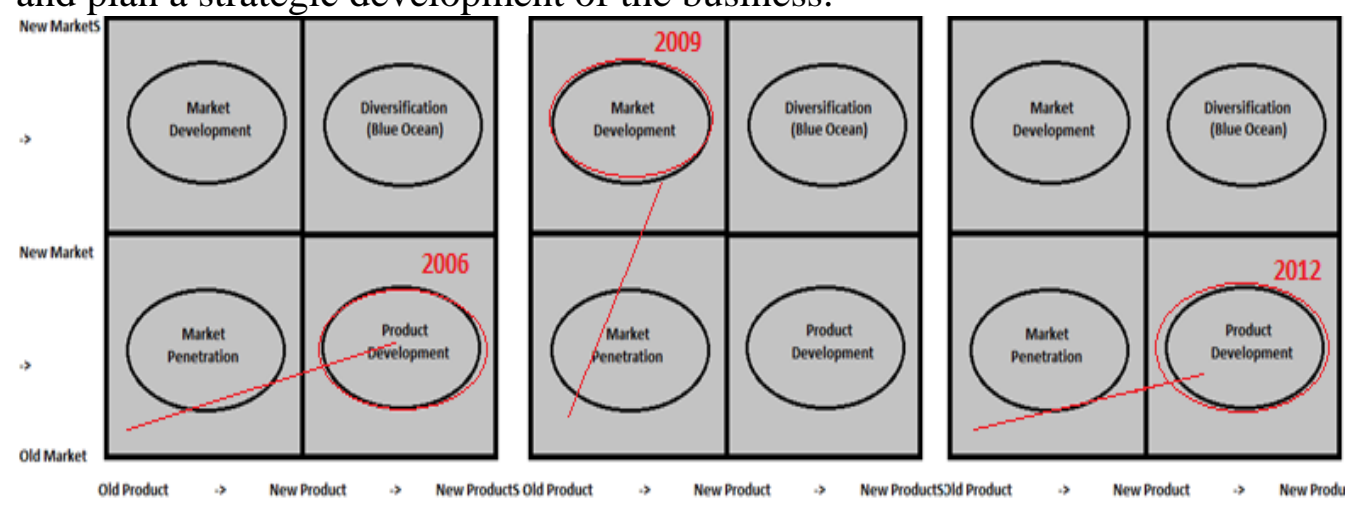



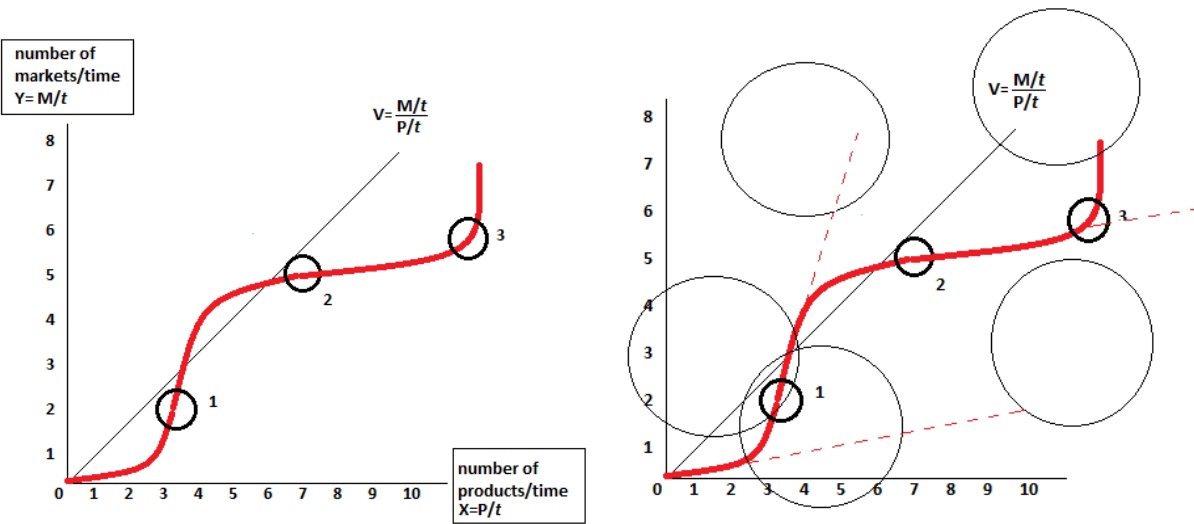

Fig. 6: Comparative Analysis pursed through Ansoff traditional and Ansoff Evolved for Company "A"

$1 \mathrm{X}=$ unit considered is product/year (number of products - courses in a certain timeframe)

$1 \mathrm{Y}=$ unit considered is market/year (number of markets - regionals in a certain timeframe)

$\mathrm{x} / \mathrm{y}=$ ratio of product (courses) offered per regional markets occupied in a certain timeframe and along a chronological evolution

"A" has got a development analyzed in three different moments.

- 2006: Originally its offer has consisted of only three courses, consistent along the whole phase 1 (3 years). "A" was present in only one market (regional), before understanding that this unique market (2006) was full and some kind of innovation was required.

Comparing a 4 cells-based matrix with a Cartesian plan based on spacetime, it is evident how the new matrix is necessary to analyze a possible, logical and probabilistic prospect.

- 2009: originally, the situation did not evolved in the direction of market diversification, falling into a clear "Icarus paradox". A prospect analysis would have shown the prospective evolution.

Moreover, through a Cartesian Plan based matrix, the prospect is possible (dashed lines) and represent the potential trend in each case of no external interference and the potential (dangerous) situation intervening on the business.

- 2012: the situation did not evolve and the company, insisting in his market-myopia closed its activity, reopening later on in 2014 cancelling previous programs and courses and launching new courses, again on the same very few markets.

An analysis of the prospect could show this, offering the possibility of multi-road evaluation in order to spot opportunities and right strategies. In 
conclusion, in 2006, "A" was running quickly to a situation of starvation insisting in developing new products instead to invest in different markets (opening branches or launching enrollment campaigns), in a strategic frame that recalls directly the Icarus Paradox (Miller 1990).
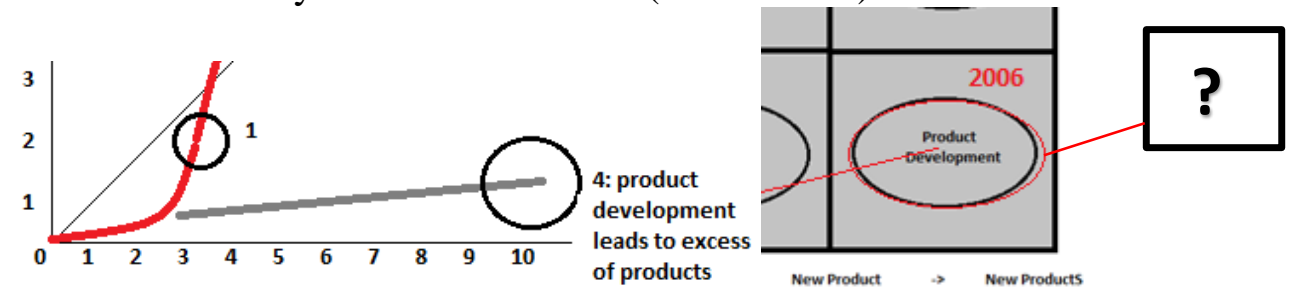

Fig. 7: Comparative analysis @ Check Point “1”, spreading product risk

Adopting the traditional model, no corrections were applied, since no recommendation or strategic analysis can be pursued or any prospect with a classic approach, if it were possible to adopt the second and hereby suggested method, a clear frame is seen and a full bunch of potential threats spotted. Moreover, no correction was practiced in 2006 and a 'grey situation" represented in the present model with line ending to number " 4 " happened (three years).

3.2 Experimentation Company "B": it is another Private School, operative and in activity for a couple of dozen years. The course of development must be read like "offer of educational products" and "markets of enrollment of students" (in the specific case of education management, it does not urge to consider markets like the physical branches open and active). The situation is checked at year 2007 drawing an Ansoff Evolved and a Ansoff Classic for comparison to analyze the actual situation and then, every two year, comparing a traditional model with the new one, spotting how practically innovation works. The check points of double analysis are numbered 1, 2, 3, 4 and 5 and they represent the main moments where a double analysis of development resulted like vital. 
(mkts $\times 10)$

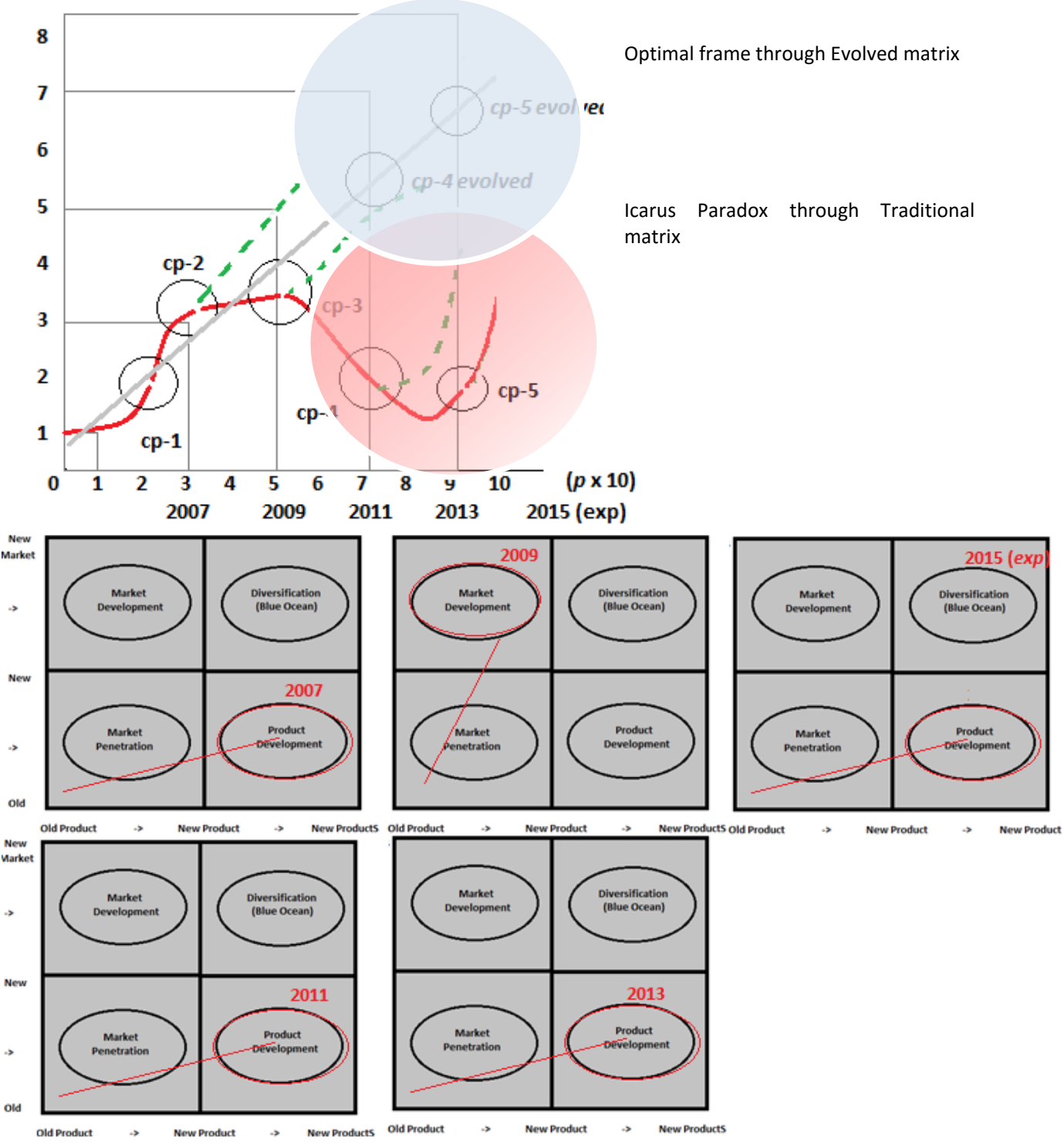

Fig. 8: Comparative Analysis pursed through Ansoff traditional and Ansoff Evolved for Company "B"

- $\quad$ Check Point-1: executed lately. School started thriving with different products in a bit concentrated market (product development), and counterbalancing this situation around 2005 with a consistent market development, mainly applying collaborations with foreign institution and affiliations. At this stage, the situation is well balanced with a broad offer of 23 courses in 18 markets (not counting the very minor ones with really tiny enrollment numbers). 
- $\quad$ Check Point-2: from this moment the situation followed a market development strategy, leading the school to counterbalance the product development with a slightly heavier development of new markets to enroll the students, filling the existing classes and working on a better margin of profitability (not showed, and actually argument for future improvements). From now on, the green line represents the best trend to follow by the company upon an Ansoff evolved matrix (that was yet under development) and the red line represents instead the real strategy followed by the school adopting a classic 4-cell matric analysis system.

- $\quad$ Check Point-3: last check point which was executed adopting the double analysis and it showed again a well-balanced development without exceeding in any of the two extremes and risking to hit the "paradox". Well, indeed is not bad to have a median-far position, if turnover and margin proves it is right (mentioned as a future improvement). Anyway during Check point-3 through the analysis it was lightly evident how the trend to launch too many product facing at the same time a stand-on of the markets' number could be slightly dangerous. In fact, even though a couple of attempts were pursued on three new markets, the fact of an endemic reductions of numbers from Japan, Korea, USA and Russian enrollment made a not-so clear situation. Green trend was not followed.

- $\quad$ Check Point-4: The red line is representing now the trend followed by the school. Strategy and mistakes of analysis caused not only a strong product development, really out of control, but also a consequential cannibalization (the main lack in market development was an unnoticed starvation and saturation) and a dangerous de-marketization on some market which was covered only with side activates. Contextually, the green line from CP-3 to CP-4 reports the recommended trend suggested to maintain a balanced development between markets and products and that can be spotted only through dynamic analysis. Note how green lines from cp-3 and cp-4 tends to a sector of market development. Simply it appears clearly wellbalanced in a product development and not risky tending to any Icarus Paradox.

- $\quad$ Check Point-5: it represents an expected trend build upon both predictive capabilities. Using a 4-cells based matrix, it is shown the actual position, without any quantitative observation or qualitative prospect about the logical and sustainable evolution. Adopting the analysis based on the evolved matrix, it is possible to see the actual trend and to apply some recommended correction, and shown again by the green line, to return the company "B" to a natural competitiveness.

In conclusion, Company "B" resulted severely self-cannibalizing its own costumers and inconsistently tied to only two markets covering over $50 \%$ of its enrollment facts. If a previous analysis were pursued through a 
more strategic tool, and beside adopting a more balanced strategy despite the adopted one, a situation of self-cannibalization would have been possibly avoided or kept under control and a more balanced trend would have been followed.

\section{Conclusion, limitations, future improvements Limitations}

The limitations concern the quantitative analysis, since it was not yet possible to work with a wider range of facts and figures, especially financial assesses. It has seemed reasonable to develop the logic system and the working framework before adding a solid number of consistent data in form of mixed factor on the axes. The most consistent was the quadricdimensional analysis

- $\quad$ Matrix analysis limited to the 4 cells-base matrix

- $\quad$ Example limited to the most popular and commonly trivial matrix of Ansoff

- $\quad$ Limited use of quantitative data inscribed on the axes, being the main purpose of the paper to show a general procedural workflow for a prospect analysis

- $\quad$ Limited or none use of financial records

\section{Future Improvements}

The most recommended improvements are those to make consistently solid and of a prospect development the matrices. The framework is still at a first, even though advanced stage, so it seems interesting to improve:

- $\quad$ Application of the Cartesian model to 9 cells-based matrix;

- $\quad$ Application of financial analysis to the Cartesian plan, to understand both strategically and financially what's going on and to give evidence of a wrong or dangerous trend;

- $\quad$ the curves' structure and the Icarus paradox's dimensions risks;

- $\quad$ the qualitative analysis to understand if this model fits consistently real needs of the industry.

\section{Conclusion}

Along with any social environment, radical mutations touched economics and marketing as well, where indeed a specific evolution involved both tools and approaches. They may rely on physioeconomics (Scaini 2011) and paraeconomics (Scaini 2015). Mutation in the environments, as in nature, are very much needed to face new market's dynamics and its targets (Fabris 2008). The research of new ways and tools is necessary to keep marketing itself up to date, as well as business processes 
and economic analysis tools. From another side, since present papers states that Marketing "is not a static area of an enterprise but a function or process" (Cozzi \& Ferrero 2004, Scaini 2011), then the search for new rules is just to be postponed in comparison with update of old ones. Rules, here, are matrices, updates are parameters adopted to make them better performing. The main takeover lies in the possibility of a prospect of the processes showed through the matrix, so result is no more a snapshot, but a course based on quantitative data. Moreover the quadric-dimensionality of the frame allows the presence of interferences from external factors, both strictly economical and paraeconomical ones, affecting the regular course and changing it into curves that require constant analysis. The new framework allows constant and reliable analysis of the whole prospect. Eventually paper proves a possible predictability through matrices, unbending themselves from mechanical consequences and stating logical, probabilistic and strategic prospects, which are able to influence the strategic planning of a company and to put into good account possible counteractions. The adoption of complex mixed factors, through holistic parameters, offers a specific vision of different threats and the logical analysis of their corrections and make it possible to adopt the matrix to record an evolution of business.

\section{References:}

General bibliograhy and webliography (preliminary readings, basic concepts):

Chisnall, P 1995, Strategic Business Marketing, Pearsons, Harlow

Collesei, U 2000, Marketing, CEDAM, Milano

Dallolio Galileo, in http://www.bottegadellaformazione.it/ (Feb, 12, 2015)

Day, GS 1984, Strategic Market Planning: The Pursuit of Competitive Advantage, West Publishing Co, Minneapolis

Hinrichsen, D \& Pritchard, AJ 2005, Mathematical Systems Theory I Modelling, State Space Analysis, Stability and Robustness, Springer-Verlag Hoffman, K \& Kunze, R 1971², Linear Algebra, Prentice - Hall, inc., Englewood Cliffs

Lambin, JJ 2008², Market-Driven Management Stategic and Operational Marketing Management, Palgrave Macmillan, London

Murray, JA \& O'Driscoll, A 1996, Strategy and Process in Marketing, Prentience Hall, Hemmel Hempstead

Pellicelli, G $2007^{12}$, Il Marketing Internazionale, Etam, Milano

Pratesi, CA, Donnelly, JH Jr. \& Peter, JP 2013, Marketing, McGraw-Hill, New York

Scaini, L. 2015, “A Comparative Study Of Physioeconomics Effects In Asia”, European Scientific Journal ESJ, 11(10). 
Scaini, L \& Navarra, D 2015, "Modern Totems And Tribalism: The Worshiping Of Brands In Asia", in European Scientific Journal 11.13 Stewart, I 2009, Dio gioca a dadi?, Bollati Boringheri, Torino

Strogatz, S 1994, Nonlinear dynamics and chaos: with applications to physics, biology chemistry and engineering, Addison Wesley

Valdani, E \& Ancarani, F 2009, Marketing Strategico, Vol. 2, Egea, Milano Weitz, BA \& Wensley, R 1998, Readings in Strategic Marketing, Dryden, Chicago

Wilson, R \& Gilligan, C \& Pearsons, D 1992, Strategic Marketing Management, Butterworth-Heinemann, Oxford

www.QuickMBA.com - Strategic Management (May 05 2015)

Riley, J 2012 in www.tutor2u.net (03 April 2015)

\section{Cited in-text bibliography:}

Alligood, KT, Sauer, TD \& Yorke, JA 2000, Chaos. An introduction to dynamical systems, Springer-Verlag

Ansoff, I 1957, Strategies for Diversification, Harvard Business Review, Vol. 35, Issue 5, pp. 113-124

Barrow, JD \& Tipler, FJ 1988, The Anthropic Cosmological Principle, Oxford University Press, Oxford

Birkhoff, G 1927, Dynamical Systems, American Mathematical Society, Providence, NY

Boundless, 2015 GE Approach, in Boundless Marketing. Boundless, 05 Jun. 2015 available in: https://www.boundless.com/marketing/textbooks/boundless-marketingtextbook/marketing-strategies-and-planning-2/strategic-views-25/geapproach-142-4048/ (09 Jun 2015)

Chow-Hou Wee 2003, Sun Zi Art of War: An Illustrated Translation with Asian Perspectives and Insights. Pearson Education Asia, Hong Kong Collins, DJ, Campbell, A \& Goold, M 1999, Harvard Business Review on Corporate Strategy, in Harvard Business Review, Paperback Series, 25 AUG 1999

Cozzi, G. \& Ferrero, G. 2004, Principi ed Aspetti Evolutivi del Marketing Aziendale, Giappichelli, Torino

Fabris, G 2008 Societing, marketing nella società postmoderna, Egea, Milano

Foegel, RW 1994, Economic Growth, Population Theory and Physiology: The Bearings of Long-Term Processes on the Making of Economic Policy, in American Economic Review, Vol. 84, No. 3, Jun., 1994, pp. 369-395 Available

from

The Article Stable URL: <http://www.jstor.org/stable/2118058> [16 June 2015] 
Henderson B, 1970 The product portfolio, available from: https://www.bcgperspectives.com/content/classics/strategy_the_product_port folio/ (12 Jun 2015)

Hirsch, MW, Smale, S \& Devaney, R 2003, Differential Equations, dynamical systems, and an introduction to chaos, Academic Press, London Johnson, G \& Scholes, K 19976, Exploring Corporate Strategy, Pearson Education, Upper Saddle River

Katok, A \& Hasselblatt, B 1996, Introduction to the modern theory of dynamical systems, Cambridge.

Kim, WC \& Mauborgne, R 2005, Blue Ocean Strategy: How to Create Uncontested Market Space and Make the Competition Irrelevant, Harvard Business School Press, Boston

Locke, C, Levine, R, Searls, D, Weinberger, D 2001, The Cluetrain Manifesto: the end of business as usual, Perseus Books Group, New York Miller, D. 1990, The Icarus Paradox, HarperBusiness, London Miller, D. 1992, The Icarus Paradox: how Exceptional Companies Bring about Their Own Downfall, in Business Horizon, 51, 1 pp 24-36

Mokwa, MP. \& Permut, SE. 1981, Government Marketing: Theory and Practice, Greenwood Publishing Group, Incorporated, Santa Barbara, CA Mokwa, MP. 1986, The Strategic Marketing Audit: An Adoption/Utilization Perspective, in Journal of Business Strategy, Vol. 6, Issue 4, pp. 88-95 Quinn, J, 1980 An Incremental Approach to Strategic Management, in McKinsey Quarterly, $4^{\text {th }}$ quarter, retrieved from: http://www3.uma.pt/filipejmsousa/ge/Quinn,\%201980.pdf

Sartori, L 1996 Understanding Relativity: A Simplified Approach To Einstein's Theories, University of California Press, Los Angeles Scaini, L 2011 Il rapporto tra l'Internazionalizzazione e la Physioeconomia, in Setup Impresa: Impresa Globale > Strategie e Analisi di Opportunita', Available from $<$ http://www.setupimpresa.it/sp/it/articolo/il-rapporto-tral'internazionalizzazione-e-la-physioeconomia.3sp> [10 May 2015]

Scaini, L 2015 To What Extent Can The Physioeconomical Factors Be Quantitatively Measured To Prove Their Influence On The Mechanical Results Of The Ayal \& Zif's Matrix?, in IMPACT: International Journal of Research in Business Management, Vol. 3, Issue 3, Mar 2015, 81-100 Thompson, J 2001, Strategic Management, Thomson Learning, New York Vermeulen, F. (4 March 2009), Business and the Icarus Paradox, in Harvard Business Review, Harvard Business Publishing, march, $4^{\text {th }}, 2009$. Vescovi T, 2008 "Il Piano di Marketing“, il Sole 24 Ore, Milano 
Table of figures

\begin{tabular}{|c|c|c|}
\hline Figure nr. & Description & page \\
\hline Figure 1: & $\begin{array}{c}\text { Adapted from Thompson, 2001: Effectiveness and Efficiency of } \\
\text { the Use of Matrices in Marketing }\end{array}$ & p.5 \\
\hline Figure 2: & Adapted from Ansoff, 1957: Ansoff matrix & p.7 \\
\hline Figure 3: & Adapted Ansoff Matrix with External Environments & p.8 \\
\hline Figure 4: & Ansoff Matrix with Mechanics Adapted to a Cartesian Plan & p.8 \\
\hline Figure 5: & Ansoff Matrix: Mechanics and Curves of Prospect Development & p.9 \\
\hline Figure 6: & $\begin{array}{c}\text { Comparative Analysis Pursued through Ansoff Traditional and } \\
\text { Ansoff Evolved for Company “A” }\end{array}$ & p.11 \\
\hline Figure 7: & $\begin{array}{c}\text { Comparative Analysis @ Check Point “1”, Spreading Product } \\
\text { Risk }\end{array}$ & p.12 \\
\hline Figure 8: & $\begin{array}{c}\text { Comparative Analysis pursued through Ansoff Traditional and } \\
\text { Ansoff Evolved for Company "B” }\end{array}$ & p.13 \\
\hline
\end{tabular}

APPENDIX (Data and facts obtained both from balance before any adjustment and from marketing officers)

Company "A" school with regional presence, Postsecondary Private Education, Italy

Check Point 1: turnover stable, margin of profit reduced by $-36 \%$ total (no single course or market analysis available or ever done, yet)

Check Point 2: turnover and margin both stable, light tendency to reduce operative margin per course

Check point 3: turnover stable, margin severely reduced by $-54 \%$ per course

Company "B" school with national presence, became international, and yet very localized, Undergraduate and Postgraduate Education, Italy

Check Point 1: Turnover and growing (no data about margin of profit)

Check Point 2: Turnover and enrollments growing (no data about margin of profit)

Check Point 3: Turnover growing (+30\% approx.), margin slightly reducing (-2\%), enrollments stable (on two-years period, growing $+20 \%$ approx.)

Check Point 4: Turnover (-3\%), enrollments (-60\% approx.) and margin ($36 \%$ ) reducing

Check Point 5: Turnover (-12\%) and margin (-28\%) reducing, enrollments (+36\%) growing 